Research Article

\title{
Cassava Wastewater and Solid Waste Leachate as Cyanogenic Substrates for the Growth of Nitrile and Linamarin-Utilizing Bacteria
}

\author{
Adewale Kayode Ogunyemi ${ }^{1 *}$, Titilola Aderonke Samuel ${ }^{2}$, Mathew Olusoji Ilori ${ }^{1}$, \\ Olukayode Oladipo Amund ${ }^{1}$ \\ ${ }^{1}$ Department of Microbiology, Faculty of Science, University of Lagos, Akoka, Lagos 100213, Nigeria \\ ${ }^{2}$ Department of Biochemistry, Faculty of Basic Medical Sciences, College of Medicine, University of Lagos, \\ Idi-Araba, Lagos 100254, Nigeria
}

Article history:

Submission October 2018

Revised January 2019

Accepted January 2019

*Corresponding author:

E-mail:

waleogunyemi2002@yahoo.com

\begin{abstract}
The direct discharge of wastewaters containing cyanogenic compounds poses severe health hazards, hence this study aimed to establish the biodegradative potential of nitrile and linamarin utilizing bacterial strains in the degradation of cyanogens in cassava wastewaters (CWW) and solid waste leachates (SWL). Glutaronitrile-utilizing bacterial strains (Bacillus sp. strain WOD8 KX774193 and Corynebacterium sp. strains WOIS2 KX774194) were isolated from solid waste leachates while linamarin-utilizing bacteria strains (Bacillus pumilus strain WOB3 KX774195 and Bacillus pumilus strain WOB7 KX774196) were isolated from cassava wastewaters. They were identified on the basis of morphological and biochemical characteristics, microscopic and 16S rRNA gene sequencing. Microbial growth assessment coupled with $\mathrm{pH}$ changes were performed under aerobic batch conditions. Growth was evaluated at intervals (2 days) by the intensity of turbidity (O.D. $600 \mathrm{~nm}$ ) in CWW and SWL media. The doubling times of strains WOD8 and WOIS2 when grown on CWW and SWL (without supplementing mineral salts medium) were 12.83 and $10.83 \mathrm{~d}$ (specific growth rate, $\mu: 0.054$ and $0.064 \mathrm{~d}-1$ ) and 20.38 and $17.77 \mathrm{~d}$ ( $\mu$ : 0.034 and $0.039 \mathrm{~d}-1$ ) respectively. Also, strains WOD8 and WOIS2 grew on supplemented CWW and SWL with doubling times of 10.04 and $9.9 \mathrm{~d}(\mu: 0.069$ and $0.070 \mathrm{~d}-1)$ and 16.12 and $16.12 \mathrm{~d}(\mu$ : 0.043 and $0.043 \mathrm{~d}-$ 1) respectively. Similarly, the doubling times of strains WOB3 and WOB7 when grown on CWW and SWL (without supplementing mineral salts medium) were 8.25 and $7.53 \mathrm{~d}(\mu: 0.084$ and $0.092 \mathrm{~d}-1)$ and 8.66 and $9.90 \mathrm{~d}(\mu: 0.080$ and 0.070 $\mathrm{d}-1)$ respectively. Whereas, the same strains had doubling times of 6.30 and 5.78 ( $\mu$ : 0.11 and $0.12 \mathrm{~d}-1$ ) and 6.30 and 9.24 ( $\mu$ : 0.11 and $0.075 \mathrm{~d}-1$ ) respectively when grown on supplemented CWW and SWL. It would appear that CWW has the highest potential as a natural growth substrate than SWL, and its use for biomass production may contribute to a reduction in the overall environmental impact generated by discarding cyanogenic residues.
\end{abstract}

Keywords: Cassava wastewater, solid waste leachate, bacterial strains, doubling times, specific growth rates, cyanogenic

\section{Introduction}

The cyanide molecule can exist in the environment as organic nitriles (R-CN) or as cyanogenic glucosides found in plants like cassava. Cyanide is also discharged into the environment due to coal combustion, refining of petroleum, iron and steel production, burning of plastics, incineration of household waste, combustion of fossil fuels, and cigarette smoking [1]. An effort of government is to boost cassava production to turn the cassava sector in Nigeria into a major player in local and international industries. Wastes generated by cassava processing pose serious environmental pollution problems [2]. The direct discharge of

\section{How to cite:}

Ogunyemi AK, Samuel TA, Amund OO, Ilori MO (2019) Cassava Wastewater and Solid Waste Leachate as Cyanogenic Substrates for the Growth of Nitrile and Linamarin-utilizing Bacteria. Journal of Tropical Life Science 9 (1): 79 - 87. doi: 10.11594/jtls.09.01.11 
wastewaters containing these nitriles and other cyanogenic compounds poses severe health hazards as most of them are highly toxic while some are mutagenic and carcinogenic in nature. The release of cyanide molecules (nitriles) into water bodies results in letting cyanide, which persists in the soil or surface water causing severe environmental pollution and hence requires detoxification. Cassava production has increased over time and Nigeria is one of the largest producers of cassava as raw material for starch and ethanol production [3, 4]. This implies a release of cyanogenic glucosides into the environment and there is a need to address this challenge. In Nigeria, there is virtually little or no official data relating to the harmful effects of toxic wastes on the environment. Biological approaches have been explored in the past to bring down the level of cyanide and nitriles in the environment. It has been found that certain microorganisms are able to detoxify cyanide from wastes by the formation of organic or inorganic acids (protons), by oxidation and reduction reactions [5, 6]. A series of organic acids are formed by bacterial (as well as fungal) metabolism resulting in organic acidolysis, complex and chelate formation $[7,8]$. Cyanide is formed as a secondary metabolite. Unfortunately, many industrial processes produce cyanide as a by-product and large quantities of it must be disposed of. Chemical methods of cyanide degradation are expensive; there have been many cases reported of cyanide pollution and the dangerous practice of 'dumping" cyanide wastes. Blumer and Haas [9] reported that its formation has an advantage for the organism by inhibiting competing microorganisms. In certain ecosystems, cyanogenic microorganisms represent a large part (up to 50\%) of the soil microbial community [10]. However, cyanide is formed at early stationery phase during growth only within a short time period [11. A large amount of cyanide formation can be generated only in certain growth media under specific conditions [12, 13]. In this connection, this study aims to increase the knowledge base of bioremediation potentials of the nitrile and linamarin-degrading organisms as well as their biodegradation of environmental nitrile-contaminants.

\section{Material and Methods \\ Microorganisms and inoculum development}

Nitrile and linamarin-utilizing bacterial strains were isolated and identified as previously described $[14,15]$. They were identified on the basis of morphological and biochemical characteristics, light microscopy and 16S rRNA gene sequencing. The bacterial isolates are Bacillus sp. strain WOD8 KX774193, Corynebacterium sp. strain WOIS2 KX774194, Bacillus pumilus strain WOB3 KX774195 and Bacillus pumilus strain WOB7 KX774196. In previous laboratory studies, these glutaronitrile utilizing strains and linamarin utilizing strains showed abilities to utilize cyanogenic compounds for growth. The isolates were resuscitated using nutrient agar and pre-enrichment was carried out using Luria-Bertani broth.

\section{Growth and substrate utilization studies}

A forty-eight hour old culture $(1.0 \mathrm{~mL})$ of each pure isolate was grown in a $250 \mathrm{~mL}$ conical flask at $30^{\circ} \mathrm{C}$ with agitation (150 rpm) in cassava wastewater (CWW) $(20 \% \mathrm{v} / \mathrm{v})$ and solid waste leachate (SWL) $(50 \% \mathrm{v} / \mathrm{v})$ of cyanogenic substrates as sole carbon sources for a period of 12 days. The mineral salts medium (MSM) (100 mL, $\mathrm{pH}$ 7.2) used for supplementation of each natural cyanogenic substrate contained; $\mathrm{K}_{2} \mathrm{HPO}_{4}$ 2.5; $\mathrm{KH}_{2} \mathrm{PO}_{4}$ 2.0; $\mathrm{MgSO}_{4} .7 \mathrm{H}_{2} \mathrm{O}$ 0.5; $\mathrm{MnSO}_{4} .4 \mathrm{H}_{2} \mathrm{O}$ 0.1; $\mathrm{CaCl}_{2} .2 \mathrm{H}_{2} \mathrm{O} \quad 0.06 ; \quad \mathrm{FeSO}_{4} .7 \mathrm{H}_{2} \mathrm{O} \quad 0.1$; $\mathrm{Na}_{2} \mathrm{MoO}_{7} .2 \mathrm{H}_{2} \mathrm{O} 0.006$. The $\mathrm{pH}$ of the medium was adjusted to 7.2. The cyanogenic CWW and SWL were tested for their ability to support the growth of the nitrile and linamarin-utilizing bacterial species. The culture fluids were sampled at an interval of $24 \mathrm{~h}$ and were tested for cyanogenic glucoside utilization and hydrogen cyanide (HCN) production over a period of 12 days. Controls (uninoculated cyanogenic medium with and without supplementing mineral salts medium, inoculated cyanogenic medium with and without supplementing mineral salts medium) were put in place and monitored to rule out contamination. Two sets of controls (the uninoculated cyanogenic medium with and without supplementing mineral salts medium and the inoculated cyanogenic medium with and without supplementing mineral salts) were put in place to monitor the extent of growth of each isolate and to rule out contamination of the setup. The extent of growth was determined by the turbidity of the growth medium compared to the controls. Bacterial growth was determined spectrophotometrically (Beckman coulter, DUR 800, Beckman coulter Inc. Fullerton, CA) at $600 \mathrm{~nm}$. 
Hydrolysis of cyanogen was measured in terms of estimation of HCN spectrophotometrically at 540 $\mathrm{nm}$ [16]. The release of HCN is the indicator of cyanide cleavage which simultaneously increases the $\mathrm{pH}$ of the medium, which was also measured throughout the experiment.

\section{Linamarin extraction}

Linamarin was extracted as previously described by Ogunyemi et al. [17] and this was used for hydrogen cyanide (HCN) assay by test organisms.

\section{HCN assay}

Culture filtrates obtained at intervals $(48 \mathrm{~h})$ from each of the culture flasks were centrifuged $\left(10,000 \times \mathrm{g}, 4^{\circ} \mathrm{C}, 10 \mathrm{~min}\right)$. The supernatants were disposed of (cell debris) and were used for the HCN assay. HCN was measured as described earlier (16) by monitoring the production of hydrocyanic acid (HCN) using a UV-visible spectrophotometer (Thermoscientific TM Spectronic GENESYS 8, Thermofisher Scientific, USA) at $540 \mathrm{~nm}$ for $15 \mathrm{~min}$. The reaction mixture $(3.0 \mathrm{ml})$ contained: culture supernatant $(1.0 \mathrm{~mL})$, linamarin $(1.0 \mathrm{~mL})$ and $1.0 \mathrm{ml}$ phosphate buffer $(0.2 \mathrm{M}, \mathrm{pH}$ 7.2). The reaction mixture was incubated at $37^{\circ} \mathrm{C}$ and the reaction was halted by the addition of 1.0 $\mathrm{mL}$ of $0.1 \mathrm{M}$ sodium carbonate $\left(\mathrm{Na}_{2} \mathrm{CO}_{3}\right)$. A standard curve enabled the conversion of the absorbance obtained to the quantity of HCN released from linamarin. One unit of enzyme activity was defined as $1.0 \mathrm{mM}$ of linamarin oxidized per min.

\section{Results and Discussion \\ Growth profiles of test organisms on cassava wastewaters and solid waste leachates}

The test organisms studied utilized cyanogens in CWW and SWL as substrate for growth. Doubling times of strains WOD8, WOIS2, WOB3 and WOB7 and their specific growth rates are presented in Table 1 while the time-course growth profiles are shown in Figures 1 and 2. The doubling times of strains WOD8 and WOIS2 when grown on CWW and SWL (without supplementing MSM) were 12.83 and $10.83 \mathrm{~d}$ (specific growth rate, $\mu: 0.054$ and $0.064 \mathrm{~d}^{-1}$ ) and 20.38 and $17.77 \mathrm{~d}\left(\mu\right.$ : 0.034 and $\left.0.039 \mathrm{~d}^{-1}\right)$ respectively. Also, strains WOD8 and WOIS2 grew on supplemented CWW and SWL with doubling times of 10.04 and $9.9 \mathrm{~d}\left(\mu\right.$ : 0.069 and $\left.0.070 \mathrm{~d}^{-1}\right)$ and 16.12 and $16.12 \mathrm{~d}\left(\mu\right.$ : 0.043 and $\left.0.043 \mathrm{~d}^{-1}\right)$ respectively. Similarly, the doubling times of strains WOB3 and WOB7 when grown on CWW and SWL (without supplementing MSM) were 8.25 and $7.53 \mathrm{~d}(\mu$ : 0.084 and $\left.0.092 \mathrm{~d}^{-1}\right)$ and 8.66 and $9.90 \mathrm{~d}(\mu: 0.080$ and $0.070 \mathrm{~d}^{-1}$ ) respectively. Whereas, the same strains had doubling times of 6.30 and $5.78(\mu$ : 0.11 and $0.12 \mathrm{~d}^{-1}$ ) and 6.30 and $9.24(\mu: 0.11$ and $\left.0.075 \mathrm{~d}^{-1}\right)$ respectively when grown on supplemented CWW and SWL. Abiona et al. [18] stated that effluent from cassava had high cyanide content and was nutritive enough to support microbial growth, which agrees with this work. Mirizadeh et al. [19] reported cyanide utilization occurred mainly during the exponential phase of growth and the highest growth rate $\left(1.23 \times 10^{8}\right)$ was obtained on day 4 of the incubation time by strain C. Bacillus species have been reported to biodegrade cyanide to non-toxic end-products by using cyanide as a nitrogen source [20,21]. Castric and Conn [22] reported the metabolism of cyanide by Bacillus and proposed the presence of a metabolic pathway involving the condensation of serine with cyanide to form betacyanoalanine followed by the hydrolysis of the latter to asparagine and then to aspartic acid. The growth of Pseudomonas in a cyanide medium requires that cyanide be enzymatically converted to ammonia which is then readily assimilated into cellular nitrogen [23, 24]. Maniyam et al. [25] reported that the cyanide biodegradation ability of Rhodococcus UKMP-5M was greatly affected by the presence of organic nutrients in the medium. In this study wastewater fortified with mineral salts medium promoted the highest growth rate of the bacteria species which simultaneously assisted complete biodegradation. Our findings corroborate with reports by Maniyam et al. [25] that observed the effect of presence of salts and glucose on microbial growth.

\section{The change in $\mathrm{pH}$}

Continuous monitoring of $\mathrm{pH}$ revealed a slight increase in $\mathrm{pH}$ from 7.2 to7.56 and 7.2 to 7.62 of the CWW medium (with and without supplementing MSM), respectively, inoculated with strain WOD8, (Figure 3). While a progressive increase in the $\mathrm{pH}$ from 7.2 to 8.34 and 7.2 to 8.88 , respectively as observed with SWL medium (with and without supplementing MSM), when inoculated with the same strain (Figure 3). Also, strain WOIS2 when cultured on CWW medium (with 
Table 1. Growth potentials of linamarin-utilizing bacteria grown on cyanogenic cassava wastewaters and solid waste leachates supplemented with or without mineral salts medium

\begin{tabular}{cllllllll}
\hline & \multicolumn{7}{c}{ Substrate } \\
\cline { 2 - 9 } Isolate & \multicolumn{2}{c}{ CWW } & \multicolumn{2}{c}{ CWW+MSM } & \multicolumn{2}{c}{ SWL } & \multicolumn{2}{c}{ SWL+MSM } \\
\cline { 2 - 9 } & $\mu\left(\mathrm{d}^{-1}\right)$ & $\mathrm{T}_{\mathrm{d}}(\mathrm{d})$ & $\mu\left(\mathrm{d}^{-1}\right)$ & $\mathrm{T}_{\mathrm{d}}(\mathrm{d})$ & $\mu\left(\mathrm{d}^{-1}\right)$ & $\mathrm{T}_{\mathrm{d}}(\mathrm{d})$ & $\mu\left(\mathrm{d}^{-1}\right)$ & $\mathrm{T}_{\mathrm{d}}(\mathrm{d})$ \\
\hline WOB3 & 0.084 & 8.25 & 0.11 & 6.30 & 0.080 & 8.66 & 0.11 & 6.30 \\
WOB7 & 0.092 & 7.53 & 0.12 & 5.78 & 0.070 & 9.90 & 0.075 & 9.24 \\
WOD8 & 0.054 & 12.83 & 0.069 & 10.04 & 0.034 & 20.38 & 0.043 & 16.12 \\
WOIS2 & 0.064 & 10.83 & 0.070 & 9.9 & 0.039 & 17.77 & 0.043 & 16.12 \\
\hline
\end{tabular}

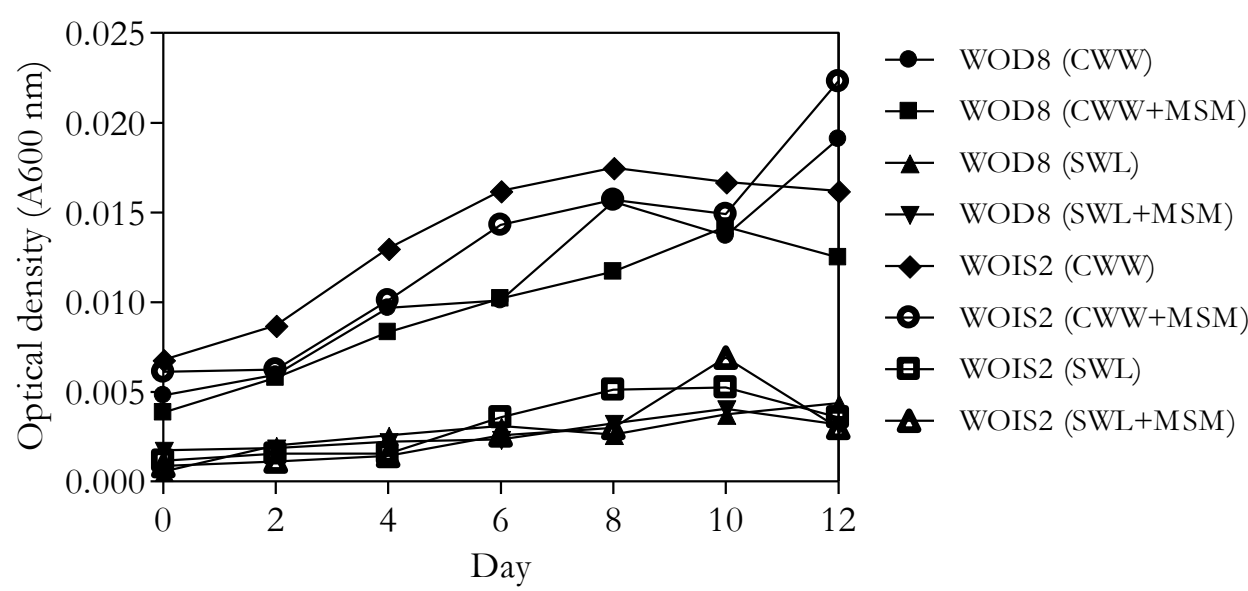

Figure 1. Growth profile of nitrile-utilizing bacteria grown on cassava wastewaters and solid waste leachates. WOD8: Bacillus sp. KX774193; WOIS2: Corynebacterium sp. KX774194; CWW: Cassava wastewater (without supplementing mineral salts medium); CWW+MSM: Cassava wastewater plus mineral salts medium (with supplementing mineral salts medium); SWL: Solid waste leachate (without supplementing mineral salts medium); SWL+MSM: Solid waste leachate plus mineral salts medium (with supplementing mineral salts medium)

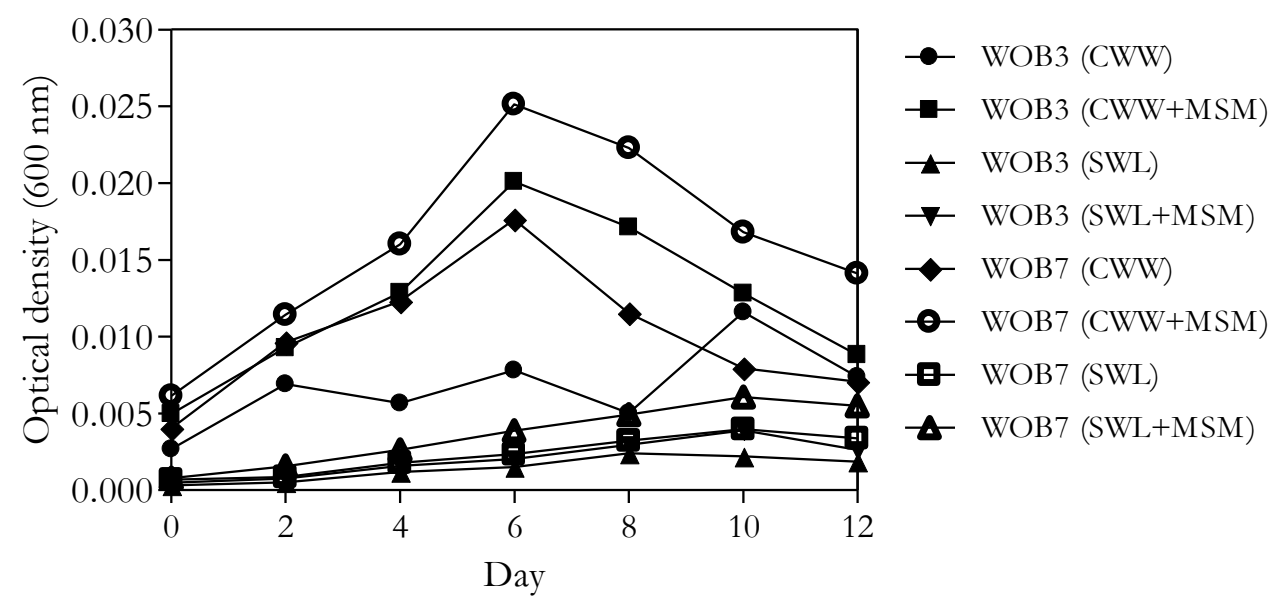

Figure 2. Growth profile of linamarin-utilizing bacteria grown on cassava wastewaters and solid waste leachates (with or without mineral salts medium). WOB3: B. pumilus KX774195; WOB7: B. pumilus KX774196; CWW: Cassava wastewater (without supplementing mineral salts medium); CWW+MSM: Cassava wastewater plus mineral salts medium (with supplementing mineral salts medium); SWL: Solid waste leachate (without supplementing mineral salts medium); SWL+MSM: Solid waste leachate plus mineral salts medium (with supplementing mineral salts medium) 


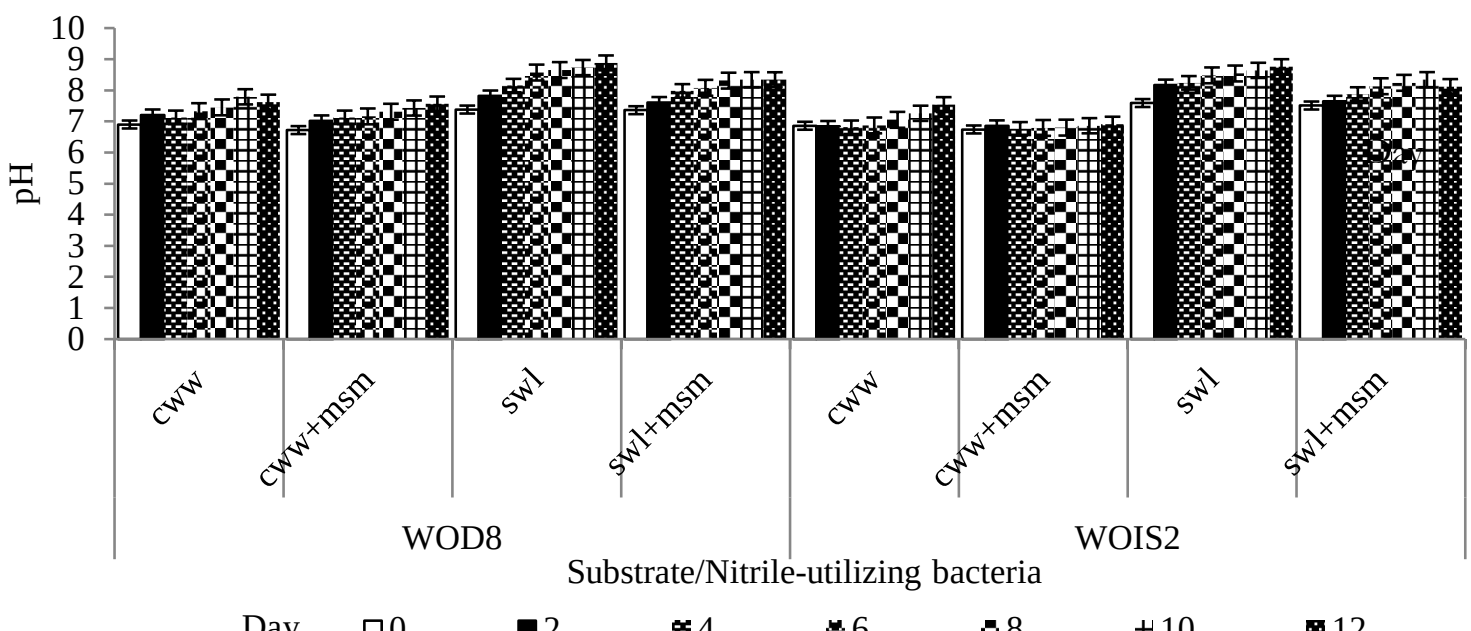

$$
\begin{array}{llllll}
\text { Day } & \square 0 & \mathbf{5} 4 & \mathbf{n} & \mathbf{n} 8
\end{array}
$$

Figure 3. pH changes of culture fluid of nitrile-utilizing bacteria on cassava wastewaters and solid waste leachates. WOD8: Bacillus sp. KX774193; WOIS2: Corynebacterium sp. KX774194; CWW: Cassava wastewater (without supplementing mineral salts medium); CWW+MSM: Cassava wastewater plus mineral salts medium (with supplementing mineral salts medium); SWL: Solid waste leachate (without supplementing mineral salts medium); SWL+MSM: Solid waste leachate plus mineral salts medium (with supplementing mineral salts medium)

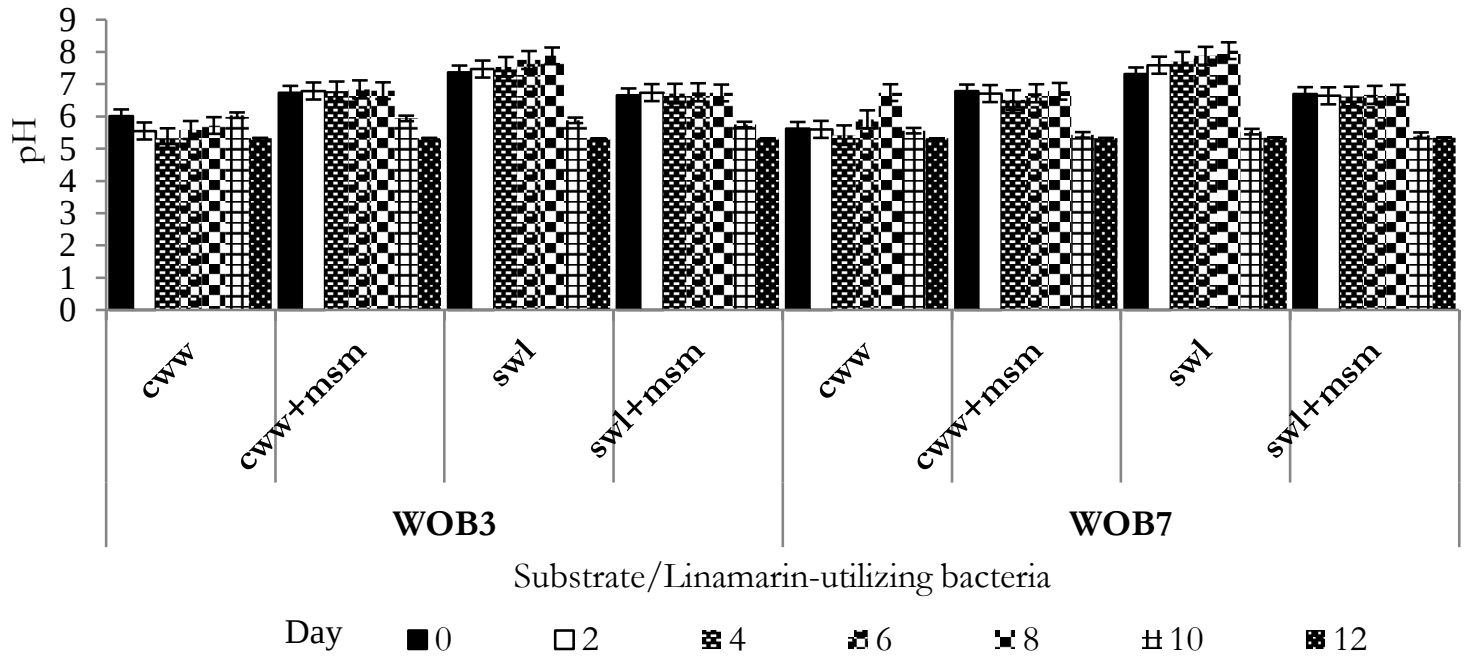

Figure 4. $\mathrm{pH}$ changes of culture fluid of linamarin-utilizing bacteria on cassava wastewaters and solid waste leachates. WOB3: B. pumilus KX774195; WOB7: B. pumilus KX774196; CWW: Cassava wastewater (without supplementing mineral salts medium); CWW+MSM: Cassava wastewater plus mineral salts medium (with supplementing mineral salts medium); SWL: Solid waste leachate (without supplementing mineral salts medium); SWL+MSM: Solid waste leachate plus mineral salts medium (with supplementing mineral salts medium)

and without supplementing MSM), the $\mathrm{pH}$ of the culture medium slightly dropped from 7.2 to 6.91 and increased from 7.2 to 7.54 , respectively. Whereas in SWL (with and without supplementing MSM) cultured 7.2 to 8.12 and 7.2 to 8.76, respectively, was noted (Figure 3). Similarly, in CWW medium (with and without supplementing MSM) inoculated with strain WOB3, the $\mathrm{pH}$ of the culture medium slightly dropped from 7.2-5.33 in both cases, respectively (Figure 4 ). While in the SWL medium (with and without supplementing MSM) inoculated with the same strain, the $\mathrm{pH}$ slightly declined from 7.2 to 5.32 in both cases, respectively (Figure 4). Whereas in CWW medium (with and without supplementing MSM) grown with WOB7, it appeared to be a slight drop 


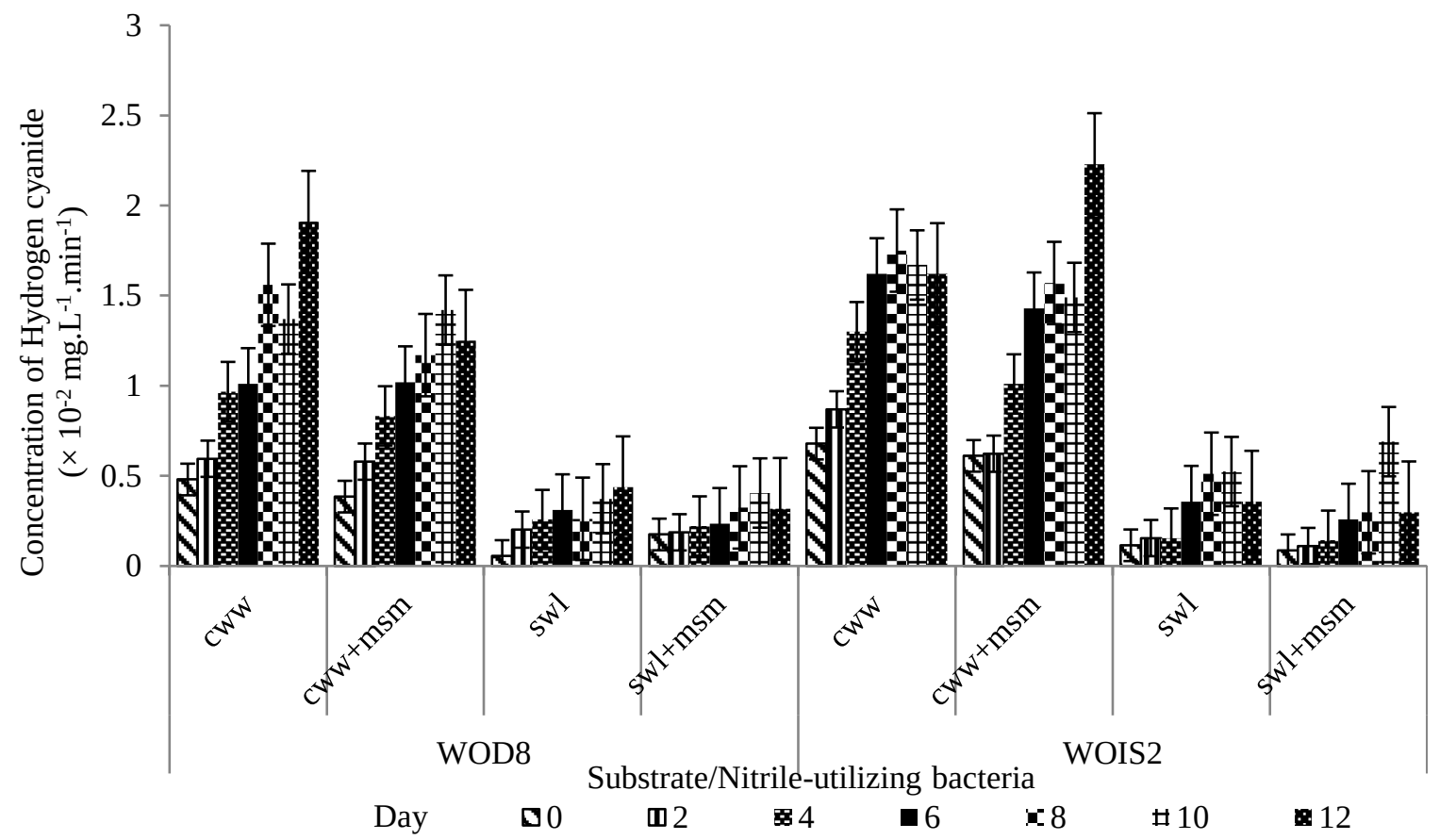

Figure 5. Hydrogen cyanide production by nitrile-utilizing bacteria when grown on cassava wastewaters and solid waste leachates. CWW: Cassava wastewater (without supplementing mineral salts medium); CWW+MSM: Cassava wastewater plus mineral salts medium (with supplementing mineral salts medium); SWL: Solid waste leachate (without supplementing mineral salts medium); SWL+MSM: Solid waste leachate plus mineral salts medium (with supplementing mineral salts medium)

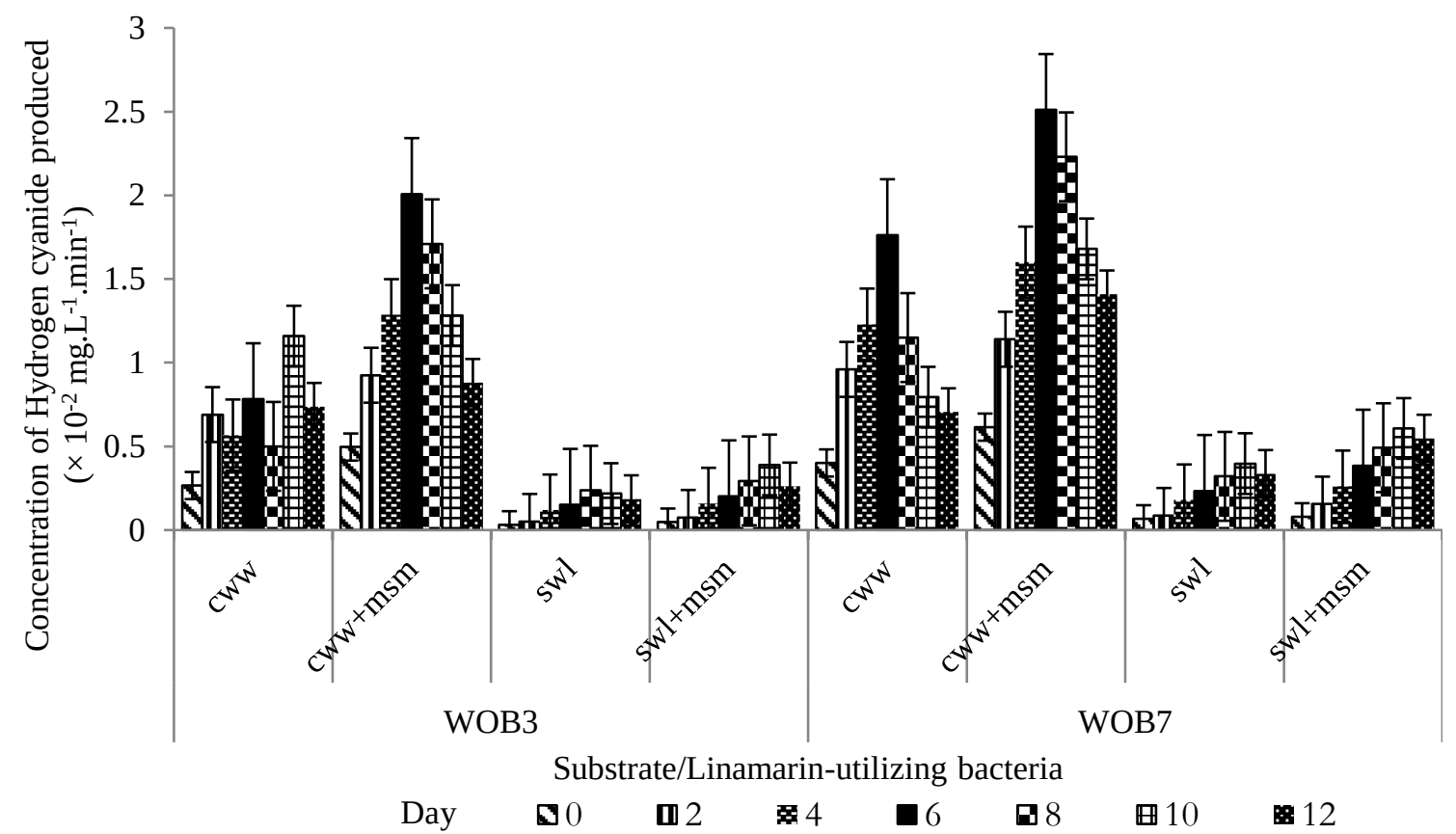

Figure 6. Hydrogen cyanide production by linamarin-utilizing bacteria when grown on cassava wastewaters and solid waste leachates. CWW: Cassava wastewater (without supplementing mineral salts medium); CWW+MSM: Cassava wastewater plus mineral salts medium (with supplementing mineral salts medium); SWL: Solid waste leachate (without supplementing mineral salts medium); SWL+MSM: Solid waste leachate plus mineral salts medium (with supplementing mineral salts medium) 
in $\mathrm{pH}$ from 7.2 to 5.33 and 7.2 to 5.32, respectively (Figure 4). While the growth of the same strain on SWL (with and without MSM), the $\mathrm{pH}$ slightly dropped from 7.2 to 5.34 in both cases, respectively (Figure 4).

Cassava wastes can be degraded with microorganisms under acidic conditions [26)]; however, the process is time-consuming and requires technical know-how. A report had that some microorganisms are able to degrade cyanide at neutral or acidic conditions, but under this condition, a high concentration of cyanide evaporates as hydrocyanic acid (HCN), a weak acid with a pKa value of 9.2 [27]. This was in line with the linamarin-utilizing bacteria which degraded cyanogens in the wastewaters at acidic ranges.

\section{Hydrocyanic acid production by the test organ- isms}

Bacillus sp. strains WOD8 and Corynebacterium sp. strain WOIS2 had accumulated $1.91 \times 10^{-}$ ${ }^{2}$ and $1.75 \times 10^{-2} \mathrm{mg} \cdot \mathrm{L}^{-1} \cdot \mathrm{min}^{-1}$ of hydrogen cyanide (HCN) on CWW (without supplementing MSM) whereas $1.42 \times 10^{-2} \mathrm{mg} \cdot \mathrm{L}^{-1} \cdot \mathrm{min}^{-1}$ and $2.23 \times 10^{-2}$ $\mathrm{mg} . \mathrm{L}^{-1} \cdot \mathrm{min}^{-1}$ of hydrogen cyanide (HCN) were obtained on supplemented CWW (Figure 5). While the same strains when grown on SWL (without supplementing MSM), produced $4.37 \times 10^{-3} \mathrm{mg} . \mathrm{L}^{-}$ ${ }^{1} \cdot \mathrm{min}^{-1}$ and $5.24 \times 10^{-3} \mathrm{mg} \cdot \mathrm{L}^{-1} \cdot \mathrm{min}^{-1}$ of $\mathrm{HCN}$ whereas $4.05 \times 10^{-3}$ and $6.9 \times 10^{-3} \mathrm{mg} \cdot \mathrm{L}^{-1} \cdot \mathrm{min}^{-1}$ of HCN had accumulated by the same strains on supplemented SWL (Figure 5). Similarly, strains WOB3 and WOB7 had produced $1.116 \times 10^{-2}$ mg. $\mathrm{L}^{-1} \cdot \mathrm{min}^{-1}$ and $1.76 \times 10^{-2} \mathrm{mg} \cdot \mathrm{L}^{-1} \cdot \mathrm{min}^{-1} \mathrm{HCN}$ when grown on CWW (without supplementing MSM) whereas the same strain liberated $1.29 \times 10^{-}$ ${ }^{2} \mathrm{mg} \cdot \mathrm{L}^{-1} \cdot \mathrm{min}^{-1}$ and $2.51 \times 10^{-2} \mathrm{mg} \cdot \mathrm{L}^{-1} \cdot \mathrm{min}^{-1} \mathrm{HCN}$ on supplemented CWW (Figure 6). While strains WOB3 and WOB7 accumulated $2.38 \times 10^{-3} \mathrm{mg} . \mathrm{L}^{-}$ ${ }^{1} \cdot \mathrm{min}^{-1}$ and $3.97 \times 10^{-3} \mathrm{mg} \cdot \mathrm{L}^{-1} \cdot \mathrm{min}^{-1} \mathrm{HCN}$ on SWL (without supplementing MSM) whereas the same strains gave $3.89 \times 10^{-3} \mathrm{mg} . \mathrm{L}^{-1} \cdot \mathrm{min}^{-1}$ and $6.07 \times$ $10^{-3} \mathrm{mg} . \mathrm{L}^{-1} \cdot \mathrm{min}^{-1} \mathrm{HCN}$ on supplemented SWL (Figure 6). Mirizadeh et al. [19] found that cyanide degradation had reached a maximum level of 96\% during the exponential phase. On a general note, nitrile-utilizing bacterial strains had declined in hydrogen cyanide production when the CWW and SWL media were supplemented with mineral salts medium. Unlike in the case of linamarin-utilizing bacterial strains, there was an increase in the production of hydrogen cyanide in supplemented media. Murugan et al. [31)] reported that B. subtilis was able to grow and produce hydrogen cyanide (HCN) in addition to ammonia during cyanogenic glycoside utilization.

In most of the recent studies, researchers carried out on cyanide removal using different bacteria under different conditions. Most of the bacteria were mesophilic while optimal temperature and $\mathrm{pH}$ ranged were about $25-30^{\circ} \mathrm{C}$ and 5.5 to 11.5 respectively [30]. Ezzi and Lynch [33] studied cyanide removal at a concentration of 2,000 ppm and successfully removed total cyanide at 90 days. Other researchers investigated the effect of lower amounts of cyanide. Naveen et al. [34] found that $83 \%$ removal of cyanide with an initial concentration of $150 \mathrm{ppm}$ at $120 \mathrm{~h}$. Özel et al. [35] investigated the use of fungi for cyanide removal and found that by using $S$. commune, P. arcularis, and G. luncidum at $\mathrm{pH} 10.5$ for $42 \mathrm{~h}$, cyanide degradation was almost $100 \%$, but the initial cyanide concentration was just $25 \mathrm{ppm}$. It showed that by increasing cyanide concentration up to $200 \mathrm{ppm}$, the removal efficiency decreased to less than $50 \%$.

\section{Conclusion}

In this study, it was established that the test organisms grew on both cassava wastewaters and solid wastewaters containing cyanogenic glucosides and used as natural substrates or as cheap alternative carbon sources. Therefore, nitrile and linamarin-utilizing bacterial species are prospective seed candidates for the bioremediation of polluted sites and in the treatment of waste effluents containing cyanogenic compounds.

\section{Acknowledgment}

The authors are grateful to Mr. Fidels Akinrindoye and Mr. Yinka Onifade of Biochemistry Department, College of Medicine, University of Lagos for technical guidance and support.

\section{References}

1. Lottermoser B (2010) Mine wastes: Characterization, treatment and environmental impacts. New York, Springer Science \& Business Media.

2. Ubalua AO (2007) Cassava wastes: Treatment options and value addition alternatives. African Journal of Biotechnology 6 (18): 2065 - 2073. doi: 10.5897/AJB2007.000-2319.

3. Sanni LO, Onadipe OO. Ilona P et al. (2009) Successes and challenges of cassava enterprises in West Africa: A case study 
of Nigeria, Benin and Sierra Leone, Ibadan, Nigeria. Ibadan, International Institute of Tropical Agriculture (IITA). pp 19.

4. Dada AD, Abayomi MA (2018) Taking local business to global market: The case for Nigerian cassava processing industry. European Journal of Business and Management 10 (15): 80 - 92.

5. Bosecker K (1997). Bioleaching: Metal solubilization by microorganisms. FEMS Microbiology Review 20: 591-604.

6. Brandl H (2001) Microbial leaching of metals. In: Rehm HJ, Reed G (Eds.), Biotechnology, vol. 10. Special processes. Weinheim, Wiley-VCH. pp. 191-224.

7. Brandl H (2001) Heterotrophic leaching. In: Gadd GM (Ed.), Fungi in bioremediation. Cambridge, Cambridge University Press. pp. 383-423.

8. Burgstaller W, Schinner F (1993) Leaching metals with fungi. Journal of Biotechnology 27 (2): 91 - 116. doi: 10.1016/01681656(93)90101-R.

9. Blumer C, Haas D (2000) Mechanism, regulation, and ecological role of bacterial cyanide biosynthesis. Archives of Microbiology 173 (3): 170 - 177. doi: 10.1007/s002039900127.

10. Kremer RJ, Souissi T (2001) Cyanide production by rhizobacteria and potential for suppression of weed seedling growth. Current Microbiology 43 (3): 182 - 186. doi: 10.1007/s002840010284.

11. Knowles C (1976) Microorganisms and cyanide. Bacteriological Reviews 40 (3): 652 - 680.

12. Castric PA (1981) The metabolism of hydrogen cyanide by bacteria. In: Vennesland B, Conn EE, Knowles CJ et al. (Eds.), Cyanide in Biology. London, Academic Press. pp. 233-261.

13. Michaels R, Corpe WA (1965) Cyanide formation by Chromobacterium violaceum. Journal of Bacteriology 89 (1): 106 - 112

14. Santoshkumar M, Veeranagouda Y, Kyoung L, Karegoudar TB (2011) Utilization of aliphatic nitrile by Paracoccus sp. SKG isolated from chemical waste samples. International Biodeterioration and Biodegradation 65 (1): 153 - 159. doi 10.1016/j.ibiod.2010.10.008.

15. Ahaotu I, Ogueke CC, Owuamanam CI et al. (2011) Protein improvement in gari by the use of pure cultures of microorganisms involved in the natural fermentation process. Pakistan Journal of Biological Sciences 14 (20): 933 - 938. doi 10.3923/pjbs.2011.933.938.

16. Oyewole OB (2001) Characteristics and significance of yeast involvement in cassava fermentation for fufu production. International Journal of Food Microbiology 65 (3): 213 - 218. doi: 10.1016/S0168-1605(01)00431-7.

17. Ogunyemi AK, Samuel TA, Buraimoh OM et al. (2017) In vitro degradation of extracted cassava linamarin by Bacillus species isolated from cassava wastewater. Egyptian Academic Journal of Biological Sciences, G. Microbiology 9 (1): 73 - 83. doi: 10.21608/eajbsg.2017.16465.

18. Abiona OO, Sanni LO, Bamgbos O (2005) An evaluation of microbial load and cyanide contents of water sources, effluents and peels three cassava processing location. Journal of Food Agriculture and Environment 3 (1): 207 - 208.

19. Mirizadeh S, Yaghmaei S, Nejad ZG (2014) Biodegradation of cyanide by a new isolated strain under alkaline conditions and optimization by response surface methodology (RSM). Journal of Environmental Health Science and Engineering 12: 85. doi: 10.1186/2052-336X-12-85.

20. Skowronski B, Strobel GA (1969) Cyanide resistance and cyanide utilization by a strain of Bacillus pumilus. Canadian Journal of Microbiology 15 (1): 93 - 98. doi: 10.1139/m69-014 27.

21. Sirianuntapiboon S, Chuamkaew C (2007) Packed cage rotating biological contractor system for treatment of cyanide waste water. Bioresource Technology 98 (2): 266 - 272. doi: 10.1016/j.biortech.2006.01.014.

22. Castric PA, Conn EE (1971) Formation of $\beta$-cyanoalanine by O-acetylserine sulfhydrylase. Journal of Bacteriology 108 (1): $132-136$.

23. Knowles CJ (1988) Cyanide utilization and degradation by microorganisms. CIBA - Foundation Symposium 140: 3 - 15.

24. Kunz DA, Wang C, Chen J (1994) Alternative routes of enzymic cyanide metabolism in Pseudomonas fluorescens NCIMB 11764. Microbiology Society 140: 1705 - 1712. doi: 10.1099/13500872-140-7-1705.

25. Maniyam MN, Sjahrir F, Ibrahim AL et al. (2013) Biodegradation of cyanide by Rhodococcus UKMP-5M. Biologia 68/2: 177 - 185. doi: 10.2478/s11756-013-0158-6.

26. Siller H, Winter J (1998) Degradation of cyanide in agroindustrial and industrial wastewater in acidification reactor or in a single-step methane reactor by bacteria enriched from soil and peels of cassava. Applied Microbiology and Biotechnology 50 (3): 384 - 389. doi: 10.1007/s002530051309.

27. Gurbuz F, Ciftci H, Akcil A (2009) Biodegradation of cyanide containing effluents by Scenedesmus obliquus. Journal of Hazardous Materials 162 (1): 74 - 79. doi: 10.1016/j.jhazmat.2008.05.008.

28. Luque-Almagro VM, Huertas MJ, Martínez-Luque $M$ et al. (2005) Bacterial degradation of cyanide and its metal complexes under alkaline conditions. Applied and Environmental Microbiology 71: 940 - 947. doi: 10.1128/AEM.71.2.940-947.2005.

29. Adjei MD, Ohta Y (1999) Isolation and characterization of a cyanide utilizing Burkholderia cepacia strain. World Journal of Microbiology and Biotechnology 15 (6): 699 - 704. doi: 10.1023/A:1008924032039.

30. Dumestre A, Chone T, Portal J et al. (1997) Cyanide degradation under alkaline conditions by a strain of Fusarium solani isolated from contaminated soils. Applied and Environmental Microbiology 63: 2729 - 2734

31. Murugan K, Sekar K, Al-Sohaibani S (2012) Detoxification of cyanides in cassava flour by linamarase of Bacillus subtilis KM05 isolated from cassava peel. African Journal of Biotechnology 11 (28): 7232 - 7237. doi: 10.5897/AJB11.8 
32. Moradkhani M, Yaghmaei S, Nejad ZG (2018) Biodegradation of cyanide under alkaline conditions by a strain of Pseudomonas putida isolated from gold mine soil and optimization of process variables through response surface methodology (RSM). Periodica Polytechnica Chemical Engineering 62 (3): 265 - 273. doi: 10.3311/PPch.10860.

33. Ezzi MI, Lynch JM (2005) Biodegradation of cyanide by Trichoderma spp. and Fusarium spp. Enzyme and Microbial
Technology $36 \quad$ (7): $849 \quad-\quad 854 . \quad$ doi: 10.1016/j.enzmictec.2004.03.030.

34. Naveen D, Majumder CB, Mondal P, Shubha D (2011) Biological treatment of cyanide containing wastewater. Research Journal of Chemical Sciences 1 (7): 15 - 21.

35. Özel YK, Gedikli S, Aytar P et al. (2010) New fungal biomasses for cyanide biodegradation. Journal of Bioscience and Bioengineering 110 (4): 431 - 435. doi: 10.1016/j.jbiosc.2010.04.011. 
This page is intentionally left blank. 